\title{
INFECTION AS THE CAUSE OF PERINATAL MORTALITY IN LATVIA
}

\author{
Ivanda Franckeviča ${ }^{1,2}$, Liene Rucka ${ }^{3}$, Santa Smilga ${ }^{3}$, Agnese \\ ANNA JAUNĀKA $\bar{A}^{3}$ \\ ${ }^{1}$ Department of Pathology, Rīga Stradiňš University, Riga, Latvia \\ ${ }^{2}$ Children's Clinical University Hospital, Riga, Latvia \\ ${ }^{3}$ Faculty of Medicine, Rìga Stradiňš University, Riga, Latvia
}

\begin{abstract}
Infection is one of the leading causes of perinatal mortality worldwide accounting for $36 \%$ of cases. Perinatal mortality in Latvia is slowly decreasing: from 7.3 per 1000 live births in 2013 to 6.7 per 1000 live births in 2015. Intrauterine infection still is a global problem and a significant factor that affects morbidity and mortality of the mother and the child.

This study includes data about the cause of death, including infections, from 417 autopsy protocols of all fetuses and neonates between 22 weeks of gestation and $<7$ days postpartum from 2013 to 2015 .

The main cause of perinatal mortality was antenatal fetal asphyxia in $50 \%(n=210)$, followed by infections $-39 \%(n=163)$, including cases of chorioamnionitis. The highest mortality rate was found in the $22^{\text {nd }}-27^{\text {th }+6}$ (i.e. 27 full weeks and 6 days) gestational weeks $-32 \%$ of cases $(n=135)$. Intrauterine pneumonia accounted for $24 \%(n=39)$ of all the infection caused deaths, meconium aspiration pneumonia - 0.04\% $(n=6)$, early neonatal sepsis $0.03 \%(\mathrm{n}=4)$ and specific infections like syphilis and cytomegalovirus $-0.02 \%$ $(\mathrm{n}=3)$. Histological examination of the placenta, the placental cord and fetal membranes was made in $61 \%(n=255)$ of cases, and $19.6 \%(n=50)$ of them had an infection.
\end{abstract}

Key words: perinatal mortality; infection; chorioamnionitis; autopsy

\section{INTRODUCTION}

Infection is one of the leading causes of perinatal mortality worldwide accounting for $36 \%$ of cases (including sepsis, pneumonia, tetanus and diar- 
rhoea), followed by conditions related to preterm labour (28\%), and birth asphyxia (23\%). Although most of the perinatal deaths occur in low-income and middle-income countries, intrauterine infection still is a global problem and a significant factor that affects morbidity and mortality of the mother and the child [13].

Incidence of perinatal mortality in the Baltic states is slowly decreasing. If we compare perinatal mortality in the Baltic states from 2010 to 2014, Latvia had the highest perinatal mortality incidence, ranging from 8.2 per 1000 live births in 2010 to 5.2 per 1000 live births in 2014. Estonia had the lowest perinatal mortality, which probably correlates with differences in the healthcare system and medical accessibility. In 2010 perinatal mortality incidence in Estonia was 5.7 per 1000 live births, but in 2014 it was 3.2 per 1000 live births. Perinatal mortality incidence in Lithuania through these years remained approximately the same - 5.6 per 1000 live births in 2010 and 4.6 per 1000 live births in 2014 . The highest incidence in Latvia was in 2011 when perinatal mortality reached 9.3 per 1000 live births [6-10].

In Europe, $35.1 \%$ of fetal deaths occur at $22-27^{+6}$ weeks of gestation, but $28.0 \%$ of fetuses die at term ( $\geq 37$ weeks of gestation) [1]. It is known that one of the causes of fetal death is chorioamnionitis, which can cause stillbirth by several mechanisms - direct fetal infection (e.g. aspiration of infected amniotic fluid), severe maternal illness and placental damage. Untreated infection can also cause preterm labour - therefore the newborn is more susceptible to infectious diseases and may develop early-onset neonatal sepsis. The incidence of early-onset neonatal sepsis is much higher in very low birthweight infants (i.e. birthweight $<1500 \mathrm{~g}$ ), and the mortality rate is high $-13-25 \%$, with even higher rates seen in premature infants [2,4]. A study by Metcalfe et al. confirms that chorioamnionitis also increases the risk of lung diseases and perinatal death [5].

There are several ways to prevent perinatal infections, for example, screening for group B Streptococcus and giving a proper treatment during pregnancy or labour, screening for urinary tract infections, syphilis, human immunodeficiency virus infection before and during pregnancy. Gynecologists and obstetricians should also encourage women to have all the routine immunizations against childhood infections (i.e. measles, mumps, rubella, and varicella) and influenza as recommended by the American College of Obstetricians and Gynecologists and the European Board and College of Obstetrics and Gynecology [4]. 


\section{MATERIAL AND METHODS}

The retrospective study includes data from 417 autopsy protocols of all the fetuses and neonates between 22 weeks of gestation and $<7$ days postpartum in Latvia from 2013 to 2015. Out of all the autopsy protocols, we selected the ones where the cause of death was infection. We analysed such parameters as location, the perinatal period, weeks of gestation, sex, results of histological examination of the placenta. Afterwards, descriptive statistical analysis was performed using the program MS Excel. The study was approved by the Riga Stradiņš University Ethics Committee.

\section{RESULTS}

\section{Perinatal mortality in Latvia}

In Latvia, most of the stillbirths and early neonatal deaths took place in Perinatal Care Units, approximately half of them, in the Perinatal Care Units in Riga (i.e. Riga Stradiņš Clinical University Hospital and Riga Maternity Hospital - in $2013-53.6 \%(\mathrm{n}=75)$, in $2014-57.2 \%(\mathrm{n}=79)$ and in $2015-48.2 \%$ $(n=67)$. About $5 \%$ of perinatal deaths took place in the Children's Clinical University Hospital Neonatal Intensive Care Unit - 3.6\% ( $n=5), 2.9 \%(n=4)$ and $5.8 \%(n=8)$ from 2013 to 2015 respectively.

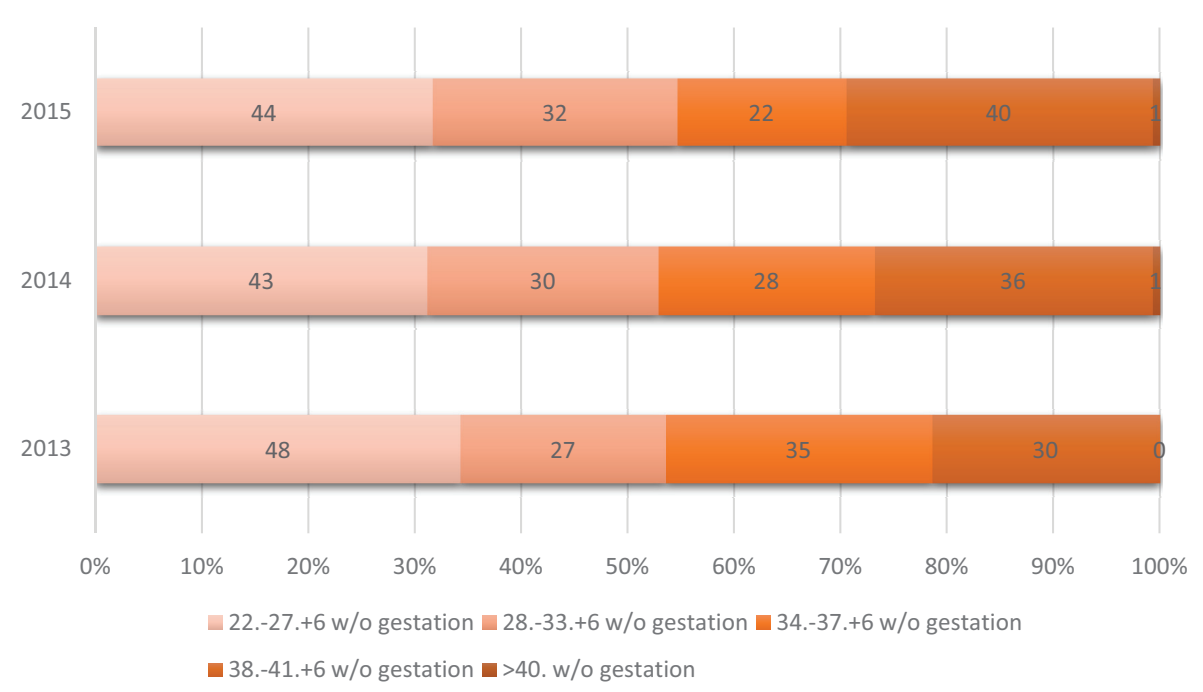

Figure 1. Distribution of weeks of gestation at the time of death from 2013 to 2015. 


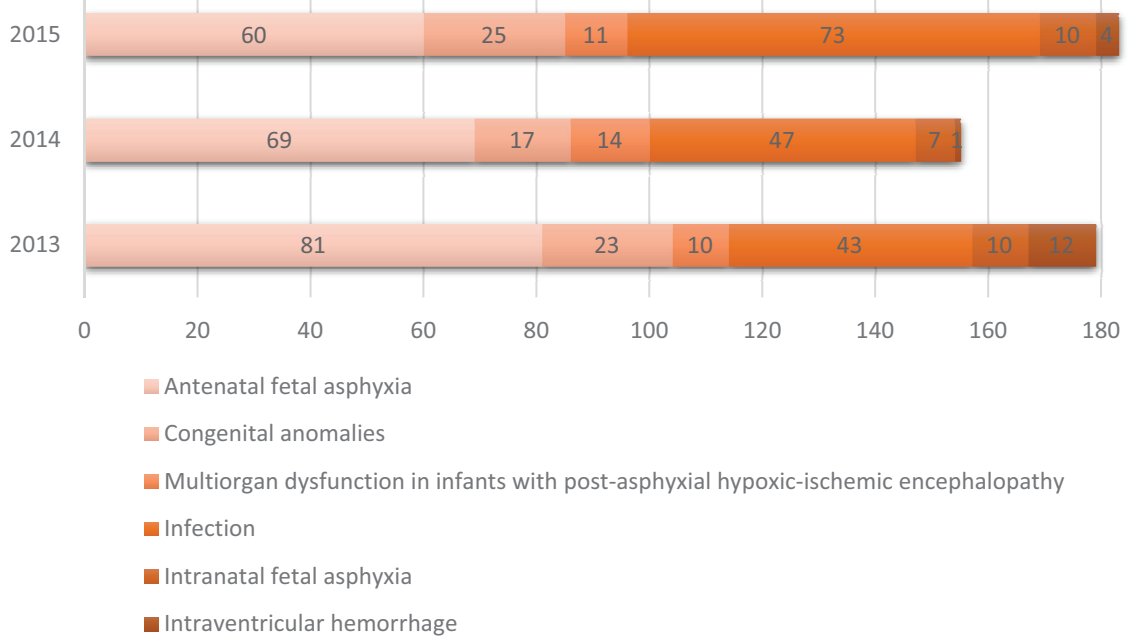

Figure 2. Causes of perinatal mortality from 2013 to 2015.

From 2013 to $2015,67.1 \%(n=94), 63.8 \%(n=88)$ and $59.0 \%(n=82)$ of perinatal deaths were antenatal. The highest mortality was found in those born preterm (Fig. 1) - the same is found in literature. About one third of perinatal deaths each year are seen in groups of extremely preterm babies (i.e. the $22^{\text {nd }}-27^{\text {th }+6}$ weeks of gestation). More than a half of the patients were male - in $2013-56.4 \%(n=79)$, in $2014-59.4 \%(n=82)$ and in $2015-59.0 \%(n=82)$ of the cases. One case of indefinite sex was found in 2015.

The three leading causes of perinatal mortality in Latvia were antenatal fetal asphyxia (i.e. stillborn), infections and congenital anomalies, including chromosomal defects, congenital heart defects, congenital central nervous system defects, etc. Figure 2 shows that, over the years, perinatal mortality caused by antenatal fetal asphyxia has been decreasing.

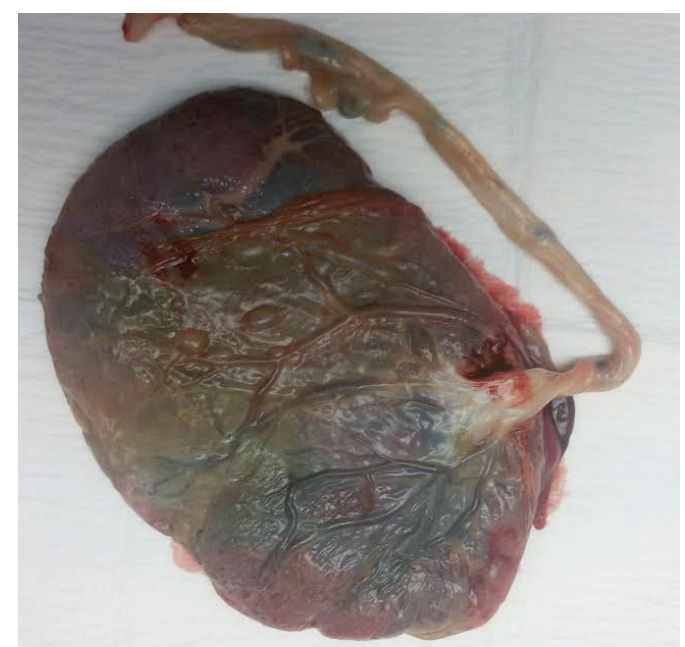

Figure 3. Gross pathology of chorioamnionitis. 
In 2015, histological examination of the placenta was performed in $73.5 \%$ $(\mathrm{n}=102)$ of cases. In the previous years, the rate of histological examination was lower - in 2013 it was $47.1 \%(n=66)$ and in $2014-64.9 \%(n=87)$ of cases. Out of all the cases, chorioamnionitis was found in $39 \%(n=26), 38 \%(n=33)$ and $56 \%(\mathrm{n}=57)$ in from 2013 to 2015 respectively (Fig. 3)

\section{Infection-caused perinatal mortality}

Through the years, the total number of perinatal mortality cases has remained approximately the same, but there has been an increase in infection-caused deaths, with the highest number in 2015 (Fig. 4).

Infection-caused perinatal mortality was more common in extremely preterm infants, followed by those born at term. In the preterm group, infection could be either the direct cause of death or the cause of premature labour resulting in other life-threatening conditions of prematurity (Fig. 5).

Sex distribution in this category was the same as in overall perinatal mortality, that is - mortality due to infections is more common in males. From 2013 to $2015-58.1 \%(n=25), 55.3 \%(n=26)$ and $58.9 \%(n=43)$ of patients were male.

Histology of placenta had been made in most cases of infection-caused perinatal mortality, and in about $90 \%$ of cases inflammatory processes like various stages of chorioamnionitis, umbilical arteritis, phlebitis and funisitis were

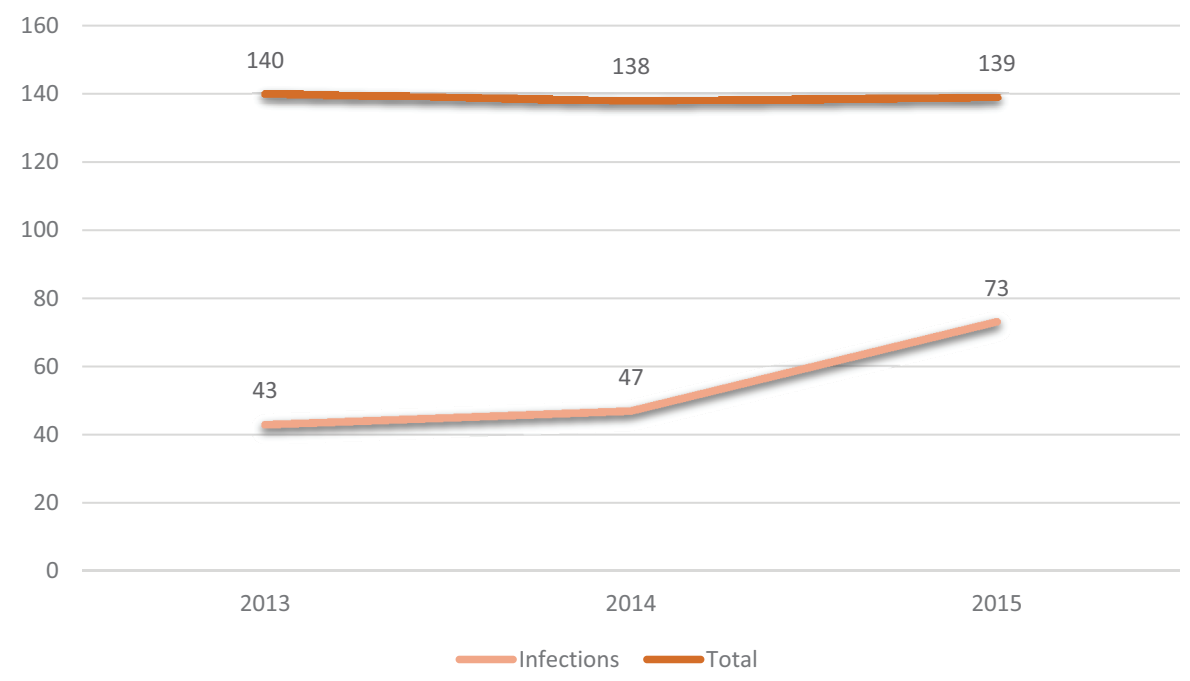

Figure 4. Infection-caused perinatal mortality compared to total perinatal mortality from 2013 to 2015. 
found (Fig. 6). All the cases of chorioamnionitis were included in this study as infection-caused deaths.

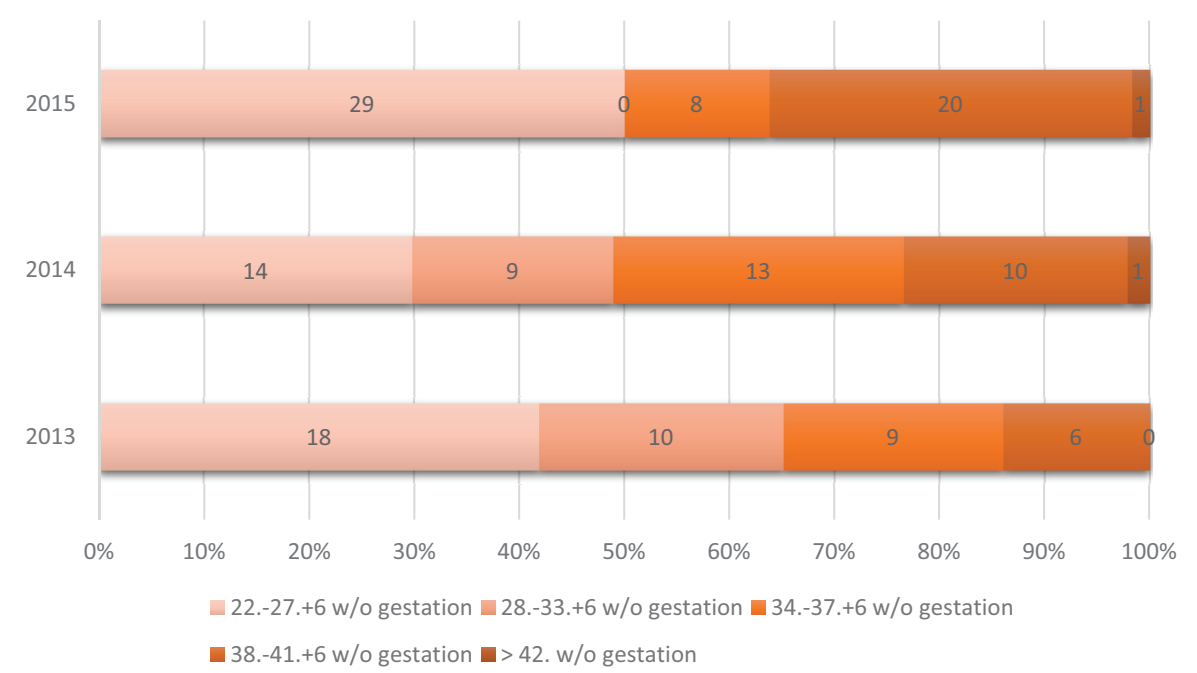

Figure 5. Distribution of weeks of gestation at the time of death in the group of infectioncaused perinatal mortality from 2013 to 2015.

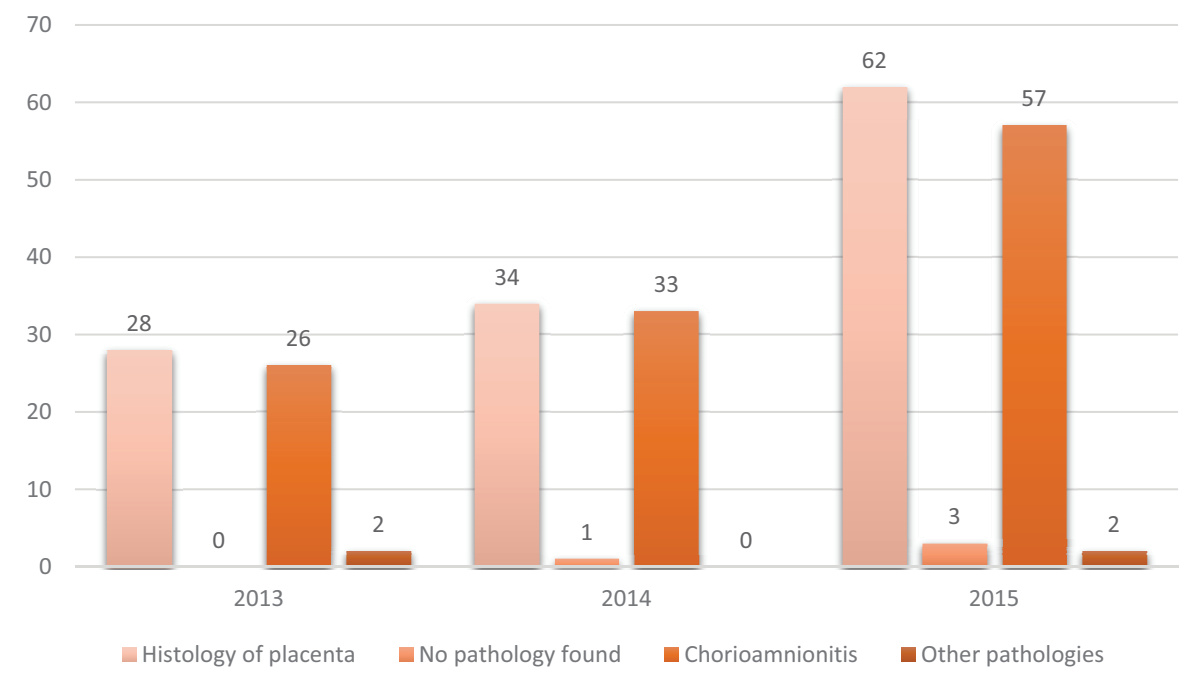

Figure 6. Results of histological examination of placenta in group of infection caused perinatal mortality, year 2013 to 2015. 
Among various infectioncaused pathologies, the most common was intrauterine pneumonia - 33\% $(\mathrm{n}=14)$ in 2013, $9 \%(n=4)$ in 2014 and $29 \%(n=21)$ in 2015 (Fig. 7$)$. Early-onset neonatal sepsis and meconium aspiration pneumonia were less common. The incidence of earlyonset neonatal sepsis in 2013 was $5 \%(n=2)$, in $2014-2 \%$ $(\mathrm{n}=1)$, and in 2015 it was $1 \%$ $(\mathrm{n}=1)$. Meconium aspiration

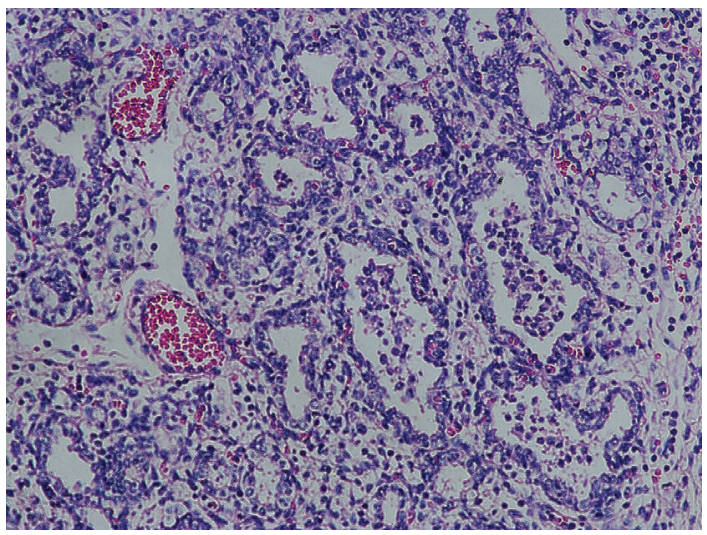

Figure 7. Intrauterine pneumonia - the main reason of infection-caused perinatal death. Hematoxylin-eosin, magnification $\times 200$. pneumonia was the cause of death in $2 \%(n=1)$ of cases in $2013,4 \%(n=2)$ of cases in 2014 and $4 \%(n=3)$ of cases in 2015. In 2014, there was one case of TORCH syndrome (i.e. a complex described by clinically similar congenital infections caused by Toxoplasma gondii, rubella virus, cytomegalovirus, and herpes simplex virus, types 1 and 2), and in 2015, one case of syphilis and one case of cytomegalovirus.

\section{DISCUSSION}

Half of all the perinatal deaths took place in the Perinatal Care Units in Riga, mainly because these hospitals are in the capital of Latvia with the highest population, and one of the hospitals is a third-level perinatal care centre where complicated pregnancies and labours take place. Children's Clinical University Hospital had the lowest number of cases because usually newborns are transferred to this hospital seven days postpartum, and only severe cases when special medical care must be provided are transferred immediately after birth.

The decrease in deaths caused by antenatal fetal asphyxia may be explained by the fact that in November 2012 the Latvian Society of Neonatologists published recommendations for neonatal hypothermia, thereby increasing neonatal survival [3].

In the three-year period from 2013 to 2015, infection was the cause of death in $39 \%$ of all the cases, including those where inflammation in the placenta (e.g. chorioamnionitis) was found. To consider placental infection as a cause 
of stillbirth, there should be placental involvement or damage. Therefore, histological examination of the placenta should be performed in all the cases of stillbirths, to rule out infection as the cause of fetal death [2].

In Europe, fetal mortality rates range from 1.5 per 1000 live births in the Czech Republic to 4.3 per 1000 live births in France, with the highest mortality rates (in France, Latvia, Brussels, Romania, and the countries of the UK) being approximately three times higher than the lowest rates [1]. In our study, there were 98 fetal deaths in 2015. The data of the Statistical Yearbook of Health Care in Latvia show that in 2015 there were 21,720 live births and stillbirths in Latvia, therefore, the fetal mortality rate in Latvia was 4.5 per 1000 live births. In 2014 there were 101 fetal deaths, that is 4.7 per 1000 live births, but in 2013 when there were 110 fetal deaths - the fetal mortality was 5.4 per 1000 live births, according to our data and the data from the Statistical Yearbook of Health Care in Latvia [11].

Inflammation was more common in extremely preterm infants. In 2015, patients born in the $22^{\text {nd }}-27^{\text {th }+6}$ weeks of gestation made $50 \%$ of infection cases, and all preterm babies born at $<37$ weeks of gestation $-68 \%$ of cases. Results from 2014 show that $77 \%$ of cases were babies born preterm, and less than one third of cases - extremely preterm babies. In $2013,86 \%$ were preterm babies, and $42 \%$ of cases were babies born in the $22^{\text {nd }}-27^{\text {th }+6}$ weeks of gestation. These results are similar to literature data that claim that almost $80 \%$ of stillbirths are preterm and about half of all stillbirths occur prior to 28 weeks [2].

The fact that in 2015 there was a decrease in the rate of mortality in postnatal period might be explained by better intrapartum and postpartum treatment with antibiotics.

The most common pathology caused by infection in our study was intrauterine pneumonia - about one third of cases, which is similar to literature data. In a review of nine studies where autopsy findings were described, the incidence of pneumonia in stillborn groups was $15-38 \%$, but in live-born neonates the incidence was $20-32 \%$ [12].

Infection of the membranes often associated with histologic chorioamnionitis frequently appears to be the cause of the preterm labour [2]. Therefore, histology of the placenta should be performed in all the cases of perinatal death so that chorioamnionitis could be excluded as the cause of death. Although the rate of examination in Latvia has increased in the past few years, it is still low $-73.5 \%$. 


\section{REFERENCES}

1. European Perinatal Health Report. Health and Care of Pregnant Women and Babies in Europe in 2010, 125-134. http://www.europeristat.com/images/doc/Peristat\%202013\%20V2.pdf

2. Gomella L.T. (2013). Neonatology: Management, Procedures, On-call Problems, Diseases, and Drugs. $7^{\text {th }}$ ed. New York: Lange Medical Books/McGrawHill Medical Pub. Division, 865-873.

3. Latvian Society of Neonatologists. (2012) Klīniskās rekomendācijas hipotermijas uzsākšanai jaundzimušajiem ar hipoksiski išēmisku encefalopātiju, 1. http://www.neonatologi.lv/wp-content/uploads/2010/01/Hipotermijasuzs\%C4\%81k\%C5\%A1 anas-rekomend\%C4\%81cijas1.pdf

4. McClure E.M., Dudley D.J., Reddy U., Goldenberg R.L. (2010). Infectious Causes of Stillbirth: A Clinical Perspective. Clinical Obstetrics and Gynecology, 53, 3, 635-645. https://doi.org/10.1097/GRF.0b013e3181eb6620

5. Metcalfe A., Lisonkova S., Sabr Y., Stritzke A., Joseph K. (2017). Neonatal respiratory morbidity following exposure to chorioamnionitis. BMC Pediatrics, 17, 128. https://doi.org/10.1186/s12887-017-0878-9

6. National Institute for Health Development of Estonia, Department of Health Statistics. The National Health Service of Latvia. Health Information Centre, Institute of Hygiene, Lithuania. (2011). Health in the Baltic Countries 2010, 21. http://www.vmnvd.gov.lv/uploads/files/4f546ace90211

7. National Institute for Health Development of Estonia, Department of Health Statistics. The Centre for Disease Prevention and Control of Latvia. Health Information Centre, Institute of Hygiene, Lithuania. (2013) Health in the Baltic Countries 2011, 21. http://sic.hi.lt/data/baltic11.pdf

8. National Institute for Health Development of Estonia, Department of Health Statistics. The Centre for Disease Prevention and Control of Latvia. Health Information Centre, Institute of Hygiene, Lithuania. (2014) Health in the Baltic Countries 2012, 21. http://sic.hi.lt/data/baltic12.pdf

9. National Institute for Health Development of Estonia. The Centre for Disease Prevention and Control of Latvia. Health Information Centre, Institute of Hygiene, Lithuania. (2015). Health in the Baltic Countries 2013, 21. http://sic.hi.lt/data/baltic13.pdf

10. National Institute for Health Development of Estonia. The Centre for Disease Prevention and Control of Latvia. Health Information Centre, Institute of Hygiene, Lithuania. (2016). Health in the Baltic Countries 2014, 16. http://sic.hi.lt/data/baltic14.pdf

11. Statistical Yearbook of Health Care in Latvia (2015). https://www.spkc.gov.lv/ lv/statistika-un-petijumi/statistika/veselibas-aprupes-statistika1

12. Taussig L.M. (2008). Pediatric Respiratory Medicine, $2^{\text {nd }}$ Edition. Mosby. 514-515. 
13. World Human Organization (2011). Newborn death and illness. http://www. who.int/pmnch/media/press_materials/fs/fs_newborndealth_illness/en/

\section{Address for correspondence:}

Liene Rucka

Faculty of Medicine

Rīga Stradin̦š University

Garā Street 33-13 Rīga, LV-1055, Latvia

E-mail: liene.rucka@gmail.com

Telephone number: +37122194808 